\title{
Factors associated with oral health-related quality of life in homeless persons: a cross-sectional study
}

Raissa Marielly Parente BERNARDINO(a) Aryvelto Miranda SILVA(a) (iD Jonathan Ferreira $\operatorname{COSTA}^{(b)}$ (D) Marcus Vinícius Barbosa SILVA(a) Isaac Torres dos SANTOS(a) Neusa Barros DANTAS NETA(c) Raimundo Rosendo PRADO JÚNIOR(a) (iD Regina Ferraz MENDES(a)

(a) Universidade Federal do Piauí - UFPI, Postgraduation Program in Dentistry, Teresina, PI, Brazil.

(b) Universidade Federal do Piauí - UFPI, Department of Restorative Dentistry, Teresina, PI, Brazil.

(c) Unifacid University Center, School of Dentistry, Teresina, PI, Brazil.

Declaration of Interests: The authors certify that they have no commercial or associative interest that represents a conflict of interest in connection with the manuscript.

\section{Corresponding Author:}

Aryvelto Miranda Silva

E-mail: aryveltomirand@gmail.com

ht1ps://doi.org/10.1590/1807-3107bor-2021.vol35.0107

Submitted: August 31, 2020

Accepted for publication: February 23, 2021

Last revision: April 19, 2021
Abstract: This study aimed to evaluate the clinical and sociodemographic factors associated with the oral health-related quality of life (OHRQoL) of homeless persons. A cross-sectional study was conducted, with participants $(n=176)$ attending a Specialized Reference Center for the Homeless Population in Teresina, Brazil. Dental caries (DMFT index, WHO criteria), periodontal disease (CPI index), and the consequences of untreated caries (PUFA index) were measured by a single calibrated examiner (Kappa $\geq 0.83$ ). Sociodemographic, oral health, and OHRQoL (OHIP-14) data were obtained through interviews. Data analysis included descriptive statistics and Poisson regression, with a significance level of $5 \%$. Most of the participants were male (86.4\%) and from the age group of 30 to 43 years (52.2\%). Mean DMFT was 11 (SD \pm 6.9$)$ and mean total PUFA score was $1.2(\mathrm{SD} \pm 2.2$ ). Most of the participants $(88.6 \%)$ had dental calculus and $8.5 \%$ and $1.7 \%$ of the sample had gingival bleeding and periodontal pocket $>3.5 \mathrm{~mm}$, respectively. The highest prevalence of negative impact in the OHRQoL was associated with females (1.4 (95\%CI 1.1-1.7)), low educational level (2.0 (95\%CI 1.3-3.0)), caries (1.6 (95\%CI 1.1-2.6)), fistulas (1.9 (95\%CI 1.3-3.1)), gingival bleeding (1.7 (95\%CI 1.1- 2.7)), dental calculus (1.8 (95\% CI 1.3-2.5)), periodontal pockets $>3 \mathrm{~mm}(1.5$ (95\%CI 1.1-2.0)), and need for extraction (2.3 (95\%CI 1.1-5.0)). In conclusion, the negative impact on the OHRQoL of homeless persons was associated with low educational level, presence of decayed teeth, gingival bleeding, and dental calculus.

Keywords: Homeless Persons; Oral Health; Quality of Life.

\section{Introduction}

The homeless population is a heterogeneous group of people in absolute poverty, with interrupted or weak family ties. ${ }^{1}$ These individuals use public places and degraded areas as temporary or permanent living spaces, as well as shelter accommodation for overnight stays or as temporary housing. ${ }^{1,2,3}$ They are often victims of discrimination and social stigma due to their dwelling status that is built around the absence of a home. Their struggle for survival, housing, and dignity demands a great deal of resiliency. ${ }^{3,4,5}$

The lack of permanent housing affects about $2 \%$ of the world population $^{6}$ and represents a risk factor for morbidities and mortality 
when compared with the general population. ${ }^{7}$ In Brazil, $70 \%$ of the estimated 100,000 people that live in homeless situations is concentrated in cities with more than one hundred thousand inhabitants. ${ }^{8}$ Being homeless creates a barrier to health services and programs; homeless persons generally only have access to emergency health services. ${ }^{9}$ Therefore, these individuals generally present a series of untreated health problems, which could be minimized by assistance, prevention, and health promotion services, including oral health services. . $^{10,11}$

Previous studies have identified a high prevalence of oral health problems in homeless individuals. ${ }^{12-17}$ However, studies on how oral diseases affect homeless persons' lives may help understand the social impact of diseases and are important to direct public health policies, in order to reduce inequalities and their impact on quality of life. ${ }^{18,19}$ Brazil has a policy for the homeless population that aims to guarantee their access to health services and programs. ${ }^{2}$ The implementation of inclusive health care actions for the homeless population is a policy that seeks to reduce the impact that the living conditions of these people have on their health and quality of life, including oral healthrelated quality of life. ${ }^{20}$

Oral health-related quality of life (OHRQoL) is a multidimensional construct of the subjective evaluation of an individual's oral health, functional and emotional well-being, expectations and satisfaction with care, and sense of self. Hence, it is negatively affected by oral disorders. ${ }^{21-24}$ Although OHRQoL of homeless populations is negatively impacted by their poor oral health conditions, the impact of the clinical and sociodemographic determinants of oral diseases on OHRQoL is not yet fully understood. Analysis of these factors could help with the formulation and assessment of oral health promotion actions and services. ${ }^{12-18}$

Therefore, this study aimed to assess the factors associated with the OHRQoL of the homeless population in a state capital in northeastern Brazil. The hypothesis that worse specific clinical and sociodemographic conditions are associated with a greater negative impact on the OHRQoL of these individuals was tested.

\section{Methodology}

\section{Ethical considerations}

This study was conducted in accordance with the Declaration of Helsinki and Resolutions 466/2012 and 510/2016 of the National Health Council of Brazil. It was approved by the Research Ethics Committee of the Federal University of Piauí (protocol No. 2,100,121). We followed the Strengthening the Reporting of Observational studies in Epidemiology (STROBE) statement in writing this manuscript. ${ }^{25}$

\section{Study design and participants}

This was a cross-sectional observational study. The study location is the only reference center for homeless persons in Teresina, Brazil. The Specialized Reference Center for Homeless Population, namely the POP Center, is a reference unit of Special Social Protection, linked to the Secretariat of Social Assistance and Citizenship of Teresina, PI. This center provides assistance for medium complexity cases of the homeless population, and consists of a staff of psychologists, social workers, and social educators. Socialization workshops are also part of the activities. Furthermore, meals, personal hygiene items and overnight shelter are offered. The POP Center works in partnership with the Street Clinic Team and provides referrals to the homeless population for public health services.

The number of all individuals enrolled at the POP Center at the beginning of the study was made available by the institution's management. A nonprobabilistic convenience sample was obtained and all individuals $(\mathrm{n}=220)$ were invited to participate in the study.

We included individuals over 18 years of age. The study did not include individuals who were uncooperative with the exams and those with hearing impairment or difficulty with verbalization.

\section{Pilot study and calibration process}

A pilot study $(n=20)$ was carried out. No change in methodology was necessary and these participants were included in the final sample.

A single examiner, a graduate student, was calibrated in two stages and advised by a researcher 
with experience in epidemiological studies and with the use of $\mathrm{DMFT}^{26}, \mathrm{CPI},{ }^{27}$ and $\mathrm{PUFA}^{28}$ indices. The first stage consisted of the presentation of diagnostic criteria established by the World Health Organization (WHO), by means of the presentation and discussion of cases with different severity levels of dental caries, clinical consequences of untreated dental caries, and periodontal health.

The second stage was performed with 20 homeless persons randomly selected in the local study, who were the same participants as those of the pilot study. This phase was carried out at the study center. The examiner independently reexamined the same individuals 2 weeks later and the results were compared. The inter-examiner kappa indices (single examiner - reference researcher) obtained were equal to or greater than 0.86 . The intra-examiner kappa indices obtained were 1.0 for DMFT, 0.92 for PUFA, and 0.83 for the CPI.

\section{Data collection}

Clinical data were collected by a single examiner (graduate student) and two properly trained assistants (undergraduate students) were responsible for annotating the data. Data were collected between January and October 2018 through oral examinations and interviews (sociodemographic data and habits related to oral health). This was complemented by OHRQoL interviews, using the OHIP-14 questionnaire. ${ }^{29}$

The examiner had to book a room in the morning or afternoon for the clinical examination with the institution's administration staff so that the examination could be carried out in the study center without interfering with the participants' daily activities. The participants were examined sitting in a chair under artificial light of a flashlight (TIKKA XPPETZL, Grenoble, France).

A flat mouth mirror (Duflex, SS White, Rio de Janeiro, Brazil), explorer probe (Duflex, SS White, Rio de Janeiro, Brazil), and periodontal probe (WHO-621, Trinity, Campo Mourão, Brazil) were used as recommended by the WHO. ${ }^{26}$ The dental caries experience was measured by the DMFT index, using the WHO criteria ${ }^{26}$ and dichotomized into presence $(\mathrm{DMFT}>0)$ or absence $(\mathrm{DMFT}=0)$ of caries experience. In addition, each component of the index was dichotomized into presence or absence of decayed teeth (caries $>0$ or caries $=0$ ), missing teeth (missing $>0$ or missing $=0$ ), or filled teeth (filled $>0$ or filled $=0) .{ }^{26}$ The clinical consequences of untreated dental caries were assessed using the PUFA index, which categorizes teeth according to pulp involvement $(\mathrm{P})$, ulceration $(\mathrm{U})$, fistulas $(\mathrm{F})$, or abscesses $(\mathrm{A}) .^{28}$ The total PUFA score was dichotomized into presence $($ PUFA $>0$ ) or absence $($ PUFA $=0$ ) of untreated dental caries. Teeth were also evaluated according to the need for treatment, namely, restoration, prosthetics, extraction, or the absence of need..$^{30}$

The evaluation of the periodontal condition regarding hygiene, bleeding, presence of calculus, or periodontal pockets was performed using the community periodontal index (CPI). ${ }^{27} \mathrm{~A}$ decision was taken to use the short CPI version, based on WHO criteria, ${ }^{31}$ due to unclear medical histories, lack of participant cooperation, dental anxiety about probing, and discomfort with dental treatment.

Oral health-related quality of life (OHRQoL) was measured using the Oral Health Impact Profile (OHIP-14) in its reduced version validated for Brazilian Portuguese. ${ }^{29}$ The reference period was the previous 12 months. The questionnaire had five answer options that followed the frequency scale, coded as never (0), rarely (1), sometimes (2), constantly (3), and always (4); the sum of the scores generated values of 0 to 56. Higher total scores reflected a higher negative impact on OHRQoL. ${ }^{29}$

After the clinical examinations, the examiner instructed the participants about oral health care. In addition, all participants received an oral hygiene kit (toothpaste, toothbrush, and dental floss) for supervised dental hygiene. Participants who needed dental treatment were referred to Basic Health Units, which are part of the national public health system, to receive dental treatment.

\section{Data analysis}

The data were analyzed using Statistical Package for the Social Sciences (IBM SPSS Version 22.0, Chicago, USA.). A descriptive analysis of the data was performed in absolute frequencies, percentages, mean and standard deviation (SD), minimum 
and maximum values. Poisson regression with robust variance in the stepwise method was used to determine the associations between the domains and the total OHIP-14 score with the independent variables. The magnitude of the association was assessed by the crude and adjusted prevalence ratio (PR), confidence intervals (95\% CI), and p-values. Variables with $\mathrm{p}$-values $\leq 0.20$ in the bivariate analysis were included in the multivariate analysis. Only variables with a value of $\mathrm{p}<0.05$ remained in the final model.

\section{Results}

Clinical examinations and interviews with 176 participants were completed (response rate $=80 \%$ ). Among those examined, $86.4 \%$ were male, $72.7 \%$ had less than eight years of schooling, and $66.5 \%$ were drug users. Most participants had at least one treatment requirement $(98.3 \%)$ and $88.6 \%$ had dental calculus (Table 1). Figure 1 shows that most participants had caries experience $(n=174)$ and the clinical consequences of untreated dental caries were present in less than half of the individuals $(n=74)$. Mean DMFT was 11 ( \pm 6.9 ). The prevalence of decayed teeth was $86.9 \%$ and of missing teeth was $86 \%$. Total PUFA score was $1.2( \pm 2.2)$, with ulcerations (33\%) being the most frequent clinical consequence.

Mean total OHIP-14 score was 18.9, with minimum and maximum values of 0 and 54 , respectively. The scores per domains are presented in Figure 2. Before the regression analysis, possible multicollinearity for DMFT and PUFA indexes was tested. The collinearities of decayed, missing, and filling with DMF-T were $\mathrm{VIF}=1.033,1.028$, and 1.059, respectively. In addition, the collinearities of pulp involvement, ulceration, and fistula in regard to total PUFA were VIF $=1.236$, 1.235 , and 1.002 , respectively. From these values, it is possible to observe that there is no multicollinearity between the total and per score component for DMFT and PUFA indexes.

Bivariate and adjusted associations for the confounding factors using Poisson regression between the domains and the total OHIP-14 score with other oral clinical conditions and sociodemographic aspects are presented in Tables 2 and 3.
Table 1. Sociodemographic and oral health-related data of the homeless participants of the study $(n=176)$.

\begin{tabular}{|c|c|c|}
\hline Variable & $\mathrm{n}$ & $\%$ \\
\hline \multicolumn{3}{|l|}{ Sex } \\
\hline Female & 24 & 13.6 \\
\hline Male & 152 & 86.4 \\
\hline \multicolumn{3}{|l|}{ Age (years) } \\
\hline Up to 29 & 44 & 25.0 \\
\hline $30-36$ & 46 & 26.1 \\
\hline $37-43$ & 46 & 26.1 \\
\hline Over 44 & 40 & 22.8 \\
\hline \multicolumn{3}{|l|}{ Marital status } \\
\hline Married/Stable relationship & 11 & 6.3 \\
\hline Single/Separated/Widowed & 165 & 93.7 \\
\hline \multicolumn{3}{|c|}{ Schooling (in years of formal study) } \\
\hline$\leq 8$ & 128 & 72.7 \\
\hline$>8$ & 48 & 27.3 \\
\hline \multicolumn{3}{|c|}{ Is a recipient of Government Financial Aid } \\
\hline No & 114 & 64.8 \\
\hline Yes & 62 & 35.2 \\
\hline \multicolumn{3}{|l|}{ Illicit drug user } \\
\hline No & 59 & 33.5 \\
\hline Yes & 117 & 66.5 \\
\hline \multicolumn{3}{|l|}{ Needs dental treatments } \\
\hline No need & 3 & 1.7 \\
\hline Restorative treatment & 12 & 6.8 \\
\hline Prosthesis & 74 & 42.0 \\
\hline Exodontia & 87 & 49.5 \\
\hline \multicolumn{3}{|l|}{ Periodontal condition } \\
\hline Healthy & 2 & 1.1 \\
\hline Bleeding & 15 & 8.5 \\
\hline Dental calculus & 156 & 88.7 \\
\hline Pocket $>3.5 \mathrm{~mm}$ & 3 & 1.7 \\
\hline Total & 176 & 100.0 \\
\hline
\end{tabular}

The "functional limitation" domain was associated with a greater negative impact on the OHRQoL in individuals with a single/separated/widowed marital status ( $\mathrm{PR}=2.6 ; 95 \% \mathrm{CI}: 1.2-5.3$ ) and with the presence of fistulas ( $\mathrm{PR}=1.9 ; 95 \% \mathrm{CI}$ : 1.3-3.1). Being a female participant ( $\mathrm{PR}=1.4 ; 95 \% \mathrm{CI}$ : 1.1-1.6), having decayed teeth $(\mathrm{PR}=1.6 ; 95 \% \mathrm{CI}$ : 1.1-2.3), gingival 


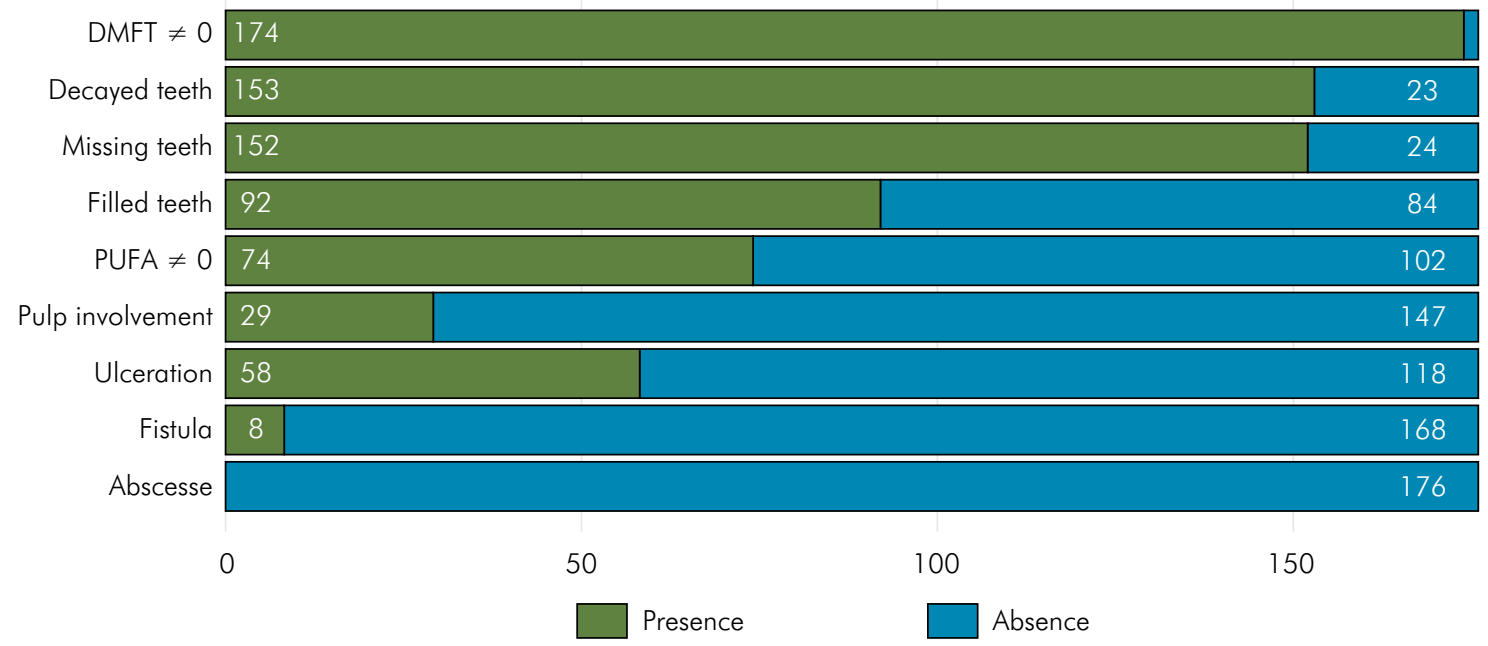

Figure 1. Oral health conditions of homeless persons, per study participants ( $n=176)$.

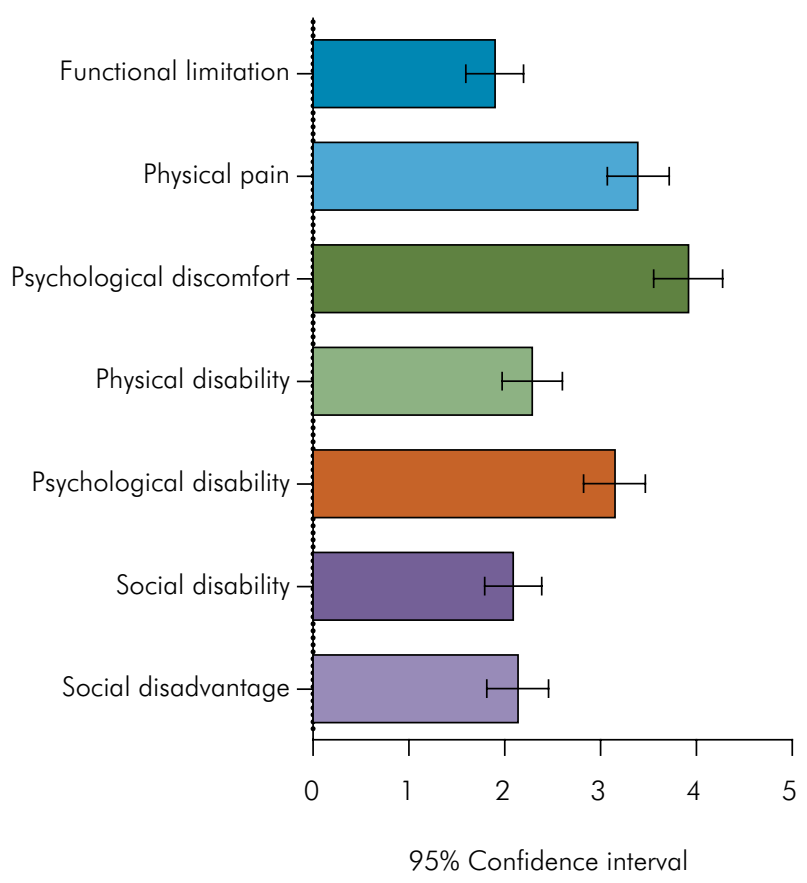

Figure 2. Mean and $95 \%$ confidence interval of OHIP- 14 scores per domains $(n=176)$.

bleeding ( $\mathrm{PR}=1.6 ; 95 \% \mathrm{CI}$ : 1.2-2.2), dental calculus $(\mathrm{PR}=1.7 ; 95 \% \mathrm{CI}: 1.7-1.9)$, and periodontal pockets $>3.5 \mathrm{~mm}(\mathrm{PR}=1.5 ; 95 \% \mathrm{CI}: 1.1-2.0)$ had a greater negative impact on the "physical pain" domain. For the "psychological discomfort" domain, a greater negative impact on OHRQoL was associated with the presence of decayed teeth $(\mathrm{PR}=1.4 ; 95 \% \mathrm{CI}$ : 1.1-1.9).
Homeless persons over the age of 44 with less than eight years of schooling had a higher negative impact on the "physical disability" and "social disadvantage" domains. "Psychological disability" was negatively associated with being female ( $P R=1.3$; 95\%CI: 1.1-1.6) and needing an extraction $(\mathrm{PR}=2.3$; $95 \%$ CI: 1.1-5.0). The "social disability" domain was associated with having less than eight years of schooling ( $\mathrm{PR}=2.0 ; 95 \% \mathrm{CI}: 1.3-3.0)$ and the presence of caries ( $\mathrm{PR}=1.6 ; 95 \% \mathrm{CI}: 1.1-2.5)$. The highest prevalence rate of the negative impact on OHRQoL, measured by the total score, was observed among homeless individuals with less than eight years of schooling (PR $=1.495 \% \mathrm{CI} 1.1-1.8)$, with decayed teeth $(\mathrm{PR}=1.4$ 95\%CI 1.1-1.8), bleeding (PR = 1.7 95\%CI 1.1-2.7), and dental calculus (PR = 1.8 95\%CI 1.3-2.5).

\section{Discussion}

The findings of the present study support our hypothesis that specific clinical and socioeconomic conditions are associated with a negative impact on the OHRQoL of homeless persons, who live in a state capital in northeastern Brazil. Homeless individuals with little schooling, decayed teeth, gingival bleeding, and dental calculus reported a greater negative impact on OHRQoL.

Almost all participants (98.9\%) had experienced dental caries, which corroborates studies in other 
Factors associated with oral health-related quality of life in homeless persons: a cross-sectional study

Table 2. Bivariate analysis between domains and total score of the OHIP- 14 instrument with sociodemographic and oral health variables $(n=176)$.

\begin{tabular}{|c|c|c|c|c|c|c|c|c|c|}
\hline \multirow{2}{*}{ Variable } & \multirow{2}{*}{$\mathrm{n}$} & $\begin{array}{l}\text { Functional } \\
\text { limitation }\end{array}$ & $\begin{array}{l}\text { Physical } \\
\text { pain }\end{array}$ & $\begin{array}{l}\text { Psychological } \\
\text { discomfort }\end{array}$ & $\begin{array}{l}\text { Physical } \\
\text { disability }\end{array}$ & $\begin{array}{l}\text { Psychological } \\
\text { disability }\end{array}$ & $\begin{array}{c}\text { Social } \\
\text { disability }\end{array}$ & $\begin{array}{c}\text { Social } \\
\text { disadvantage }\end{array}$ & Total score \\
\hline & & $\begin{array}{l}\mathrm{PR}_{\text {crude }} \\
(95 \% \mathrm{Cl})\end{array}$ & $\begin{array}{l}\mathrm{PR}_{\text {crude }} \\
(95 \% \mathrm{Cl})\end{array}$ & $\begin{array}{l}\mathrm{PR}_{\text {crude }} \\
(95 \% \mathrm{Cl})\end{array}$ & $\begin{array}{l}\mathrm{PR}_{\text {crude }} \\
(95 \% \mathrm{Cl})\end{array}$ & $\begin{array}{l}\mathrm{PR}_{\text {crude }} \\
(95 \% \mathrm{Cl})\end{array}$ & $\begin{array}{c}\mathrm{PR}_{\text {crude }} \\
(95 \% \mathrm{Cl})\end{array}$ & $\begin{array}{l}\mathrm{PR}_{\text {crude }} \\
(95 \% \mathrm{Cl})\end{array}$ & $\begin{array}{l}\mathrm{PR}_{\text {crude }} \\
(95 \% \mathrm{Cl})\end{array}$ \\
\hline \multicolumn{10}{|l|}{ Sex } \\
\hline Female & 24 & $1.3(0.8-2.1)$ & $1.4(1.1-1.7)^{*}$ & 0.9 (0.7-1.3) & $1.4(0.9-1.9)$ & $1.3(0.9-1.6)$ & $1.3(0.9-1.9)$ & $0.9(0.5-1.5)$ & $1.2(0.9-1.6)$ \\
\hline Male & 152 & 1 & 1 & 1 & 1 & 1 & 1 & 1 & 1 \\
\hline \multicolumn{10}{|l|}{ Age (years) } \\
\hline Over 44 & 40 & $1.1(0.7-1.8)$ & $0.8(0.6-1.2)$ & $1.1(0.8-1.4)$ & $1.6(1.1-2.5)^{*}$ & $1.2(0.9-1.7)$ & $1.2(0.7-1.8)$ & $1.6(0.9-2.7)$ & $1.2(0.9-1.5)$ \\
\hline $37-43$ & 46 & $1.6(1.1-2.3)^{*}$ & $0.8(0.6-1.1)$ & $1.0(0.8-1.4)$ & 1.5 (0.9-2.3) & $1.1(0.8-1.5)$ & $0.9(0.6-1.5)$ & $1.4(0.9-2.4)$ & $1.1(0.8-1.5)$ \\
\hline $30-36$ & 46 & $0.8(0.5-1.3)$ & $0.9(0.7-1.1)$ & $1.1(0.8-1.4)$ & $1.5(0.9-2.2)$ & $1.0(0.7-1.4)$ & $1.2(0.8-1.8)$ & $1.5(0.9-2.5)$ & $1.1(0.8-1.4)$ \\
\hline Up to 29 & 44 & 1 & 1 & 1 & 1 & 1 & 1 & 1 & 1 \\
\hline \multicolumn{10}{|l|}{ Marital status } \\
\hline $\begin{array}{l}\text { Married/Stable } \\
\text { relationship }\end{array}$ & 11 & $0.5(0.2-1.0)$ & $0.9(0.7-1.4)$ & $0.9(0.6-1.4)$ & $1.2(0.6-2.2)$ & $0.9(0.6-1.3)$ & $0.9(0.6-1.6)$ & $0.7(0.4-1.2)$ & $0.9(0.6-1.3)$ \\
\hline $\begin{array}{l}\text { Single/ } \\
\text { Separated/ } \\
\text { Widowed }\end{array}$ & 165 & 1 & 1 & 1 & 1 & 1 & 1 & 1 & 1 \\
\hline \multicolumn{10}{|c|}{ Schooling (in years of formal study) } \\
\hline$\leq 8$ & 128 & $1.3(0.9-1.9)$ & $1.2(0.9-1.5)$ & $1.2(0.9-1.6)$ & $1.5(1.1-2.1)^{*}$ & $1.3(1.1-1.8)^{*}$ & $2.0(1.3-3.0)^{*}$ & $1.9(1.3-2.7)^{*}$ & $1.4(1.1-1.8)^{*}$ \\
\hline$>8$ & 48 & 1 & 1 & 1 & 1 & 1 & 1 & 1 & 1 \\
\hline \multicolumn{10}{|c|}{ Is a recipient of Government Financial Aid } \\
\hline No & 62 & $1.3(0.9-1.7)$ & $1.1(0.9-1.3)$ & $1.3(1.1-1.5)^{*}$ & $1.2(0.9-1.6)$ & $1.1(0.9-1.3)$ & $1.2(0.9-1.6)$ & $1.2(0.9-1.6)$ & $1.2(0.9-1.4)$ \\
\hline Yes & 114 & 1 & 1 & 1 & 1 & 1 & 1 & 1 & 1 \\
\hline \multicolumn{10}{|l|}{ Illicit drug user } \\
\hline Yes & 117 & $1.0(0.7-1.5)$ & $1.1(0.9-1.4)$ & $1.1(0.9-1.4)$ & $1.0(0.8-1.4)$ & $1.0(0.8-1.2)$ & $1.2(0.9-1.6)$ & $1.1(0.8-1.5)$ & $1.1(0.9-1.3)$ \\
\hline No & 59 & 1 & 1 & 1 & 1 & 1 & 1 & 1 & 1 \\
\hline \multicolumn{10}{|l|}{ Decayed teeth } \\
\hline Yes & 153 & $1.5(0.9-2.3)$ & $1.6(1.1-2.4)^{*}$ & $1.3(0.9-1.7)$ & $1.5(0.9-2.3)$ & $1.3(0.9-1.9)$ & $1.5(0.9-2.3)$ & $1.1(0.7-1.7)$ & $1.4(1.1-1.8)^{*}$ \\
\hline No & 23 & 1 & 1 & 1 & 1 & 1 & 1 & 1 & 1 \\
\hline \multicolumn{10}{|l|}{ Missing } \\
\hline Yes & 152 & $1.1(0.7-1.7)$ & $0.9(0.7-1.3)$ & $1.2(0.8-1.6)$ & $1.4(0.9-2.3)$ & $1.3(0.9-1.9)$ & $1.4(0.8-2.4)$ & $1.4(0.8-2.4)$ & $1.2(0.9-1.6)$ \\
\hline No & 24 & 1 & 1 & 1 & 1 & 1 & 1 & 1 & 1 \\
\hline \multicolumn{10}{|l|}{ Filled } \\
\hline Yes & 92 & $1.1(0.8-1.5)$ & $0.9(0.7-1.1)$ & $1.0(0.8-1.2)$ & $1.1(0.8-1.4)$ & $1.0(0.8-1.3)$ & $1.0(0.8-1.4)$ & $0.9(0.7-1.2)$ & $0.9(0.8-1.2)$ \\
\hline No & 84 & 1 & 1 & 1 & 1 & 1 & 1 & 1 & 1 \\
\hline \multicolumn{10}{|c|}{ Dental caries experience } \\
\hline Yes & 174 & $0.9(0.2-3.8)$ & $1.1(0.3-4.5)$ & $2.6(0.7-10.5)$ & - & $3.2(0.8-12.7)$ & $1.4(0.3-5.6)$ & $1.1(0.3-4.3)$ & $1.7(0.4-6.9)$ \\
\hline No & 2 & 1 & 1 & 1 & & 1 & 1 & 1 & 1 \\
\hline \multicolumn{10}{|c|}{ Pulp involvement $>0$} \\
\hline Yes & 29 & $0.9(0.6-1.5)$ & $0.8(0.7-1.1)$ & $1.0(0.8-1.2)$ & $1.1(0.8-1.5)$ & $1.2(0.9-1.5)$ & $1.0(0.7-1.4)$ & $1.1(0.7-1.6)$ & $1.0(0.8-1.2)$ \\
\hline No & 147 & 1 & 1 & 1 & 1 & 1 & 1 & 1 & 1 \\
\hline \multicolumn{10}{|l|}{ Ulceration $>0$} \\
\hline Yes & 58 & $1.2(0.9-1.6)$ & $0.9(0.8-1.2)$ & $1.2(0.9-1.4)$ & $1.1(0.8-1.4)$ & $1.1(0.9-1.3)$ & $1.1(0.8-1.5)$ & $0.9(0.6-1.2)$ & $1.1(0.9-1.3)$ \\
\hline No & 118 & 1 & 1 & 1 & 1 & 1 & 1 & 1 & 1 \\
\hline
\end{tabular}




\begin{tabular}{|c|c|c|c|c|c|c|c|c|c|}
\hline \multicolumn{10}{|l|}{ Continuation } \\
\hline \multicolumn{10}{|l|}{ Fistulas $>0$} \\
\hline Yes & 8 & $2.2(1.4-3.5)^{*}$ & $1.1(0.7-1.6)$ & $1.1(0.8-1.6)$ & $1.1(0.6-1.8)$ & $1.3(0.9-1.9)$ & $0.8(0.4-1.6)$ & $1.3(0.7-2.3)$ & $1.2(0.9-1.7)$ \\
\hline No & 168 & 1 & 1 & 1 & 1 & 1 & 1 & 1 & 1 \\
\hline \multicolumn{10}{|l|}{ PUFA $>0$} \\
\hline Yes & 74 & $1.1(0.8-1.6)$ & $0.9(0.8-1.1)$ & $1.1(0.9-1.4)$ & $1.2(0.9-1.5)$ & $1.2(0.9-1.4)$ & $1.2(0.9-1.4)$ & $1.1(0.8-1.4)$ & $0.9(0.7-1.3)$ \\
\hline No & 102 & 1 & 1 & 1 & 1 & 1 & 1 & 1 & 1 \\
\hline \multicolumn{10}{|l|}{$\begin{array}{l}\text { Needs dental } \\
\text { treatments }\end{array}$} \\
\hline $\begin{array}{l}\text { Restorative } \\
\text { treatment }\end{array}$ & 12 & $0.7(0.2-2.3)$ & $1.2(0.4-3.7)$ & $0.8(0.3-2.5)$ & & $1.1(0.3-3.9)$ & $0.6(0.1-2.9)$ & $0.5(0.1-1.9)$ & $0.9(0.3-2.6)$ \\
\hline Prosthesis & 74 & $0.8(0.3-2.1)$ & $1.1(0.4-3.2)$ & $1.1(0.4-3.0)$ & & $2.2(0.9-4.9)$ & $1.1(0.5-2.7)$ & $0.9(0.4-2.5)$ & $1.3(0.6-3.0)$ \\
\hline Exodontia & 87 & $1.1(0.4-2.8)$ & $1.4(0.5-4.1)$ & $1.2(0.5-3.3)$ & & $2.7(1.2-6.1)^{*}$ & $1.5(0.6-3.5)$ & $1.2(0.5-3.2)$ & $1.6(0.7-3.8)$ \\
\hline No need & 3 & 1 & 1 & 1 & & 1 & 1 & 1 & 1 \\
\hline \multicolumn{10}{|l|}{ CPI } \\
\hline Bleeding & 15 & $1.5(0.4-6.5)$ & $1.6(1.1-2.3)^{*}$ & $3.3(0.8-13.7)$ & $0.8(0.5-1.4)$ & $3.0(0.7-12.9)$ & $1.8(0.4-7.7)$ & $2.1(0.5-9.4)$ & $1.8(0.9-3.5)$ \\
\hline $\begin{array}{l}\text { Dental } \\
\text { calculus }\end{array}$ & 156 & $1.2(0.3-4.9)$ & $1.7(1.6-1.9)^{*}$ & $4.0(1.0-16.1)$ & $1.2(1.1-1.3)^{*}$ & $3.2(0.8-12.9)$ & $1.4(0.3-5.5)$ & $2.2(0.5-8.7)$ & $1.9(1.1-3.3)^{*}$ \\
\hline $\begin{array}{l}\text { Pocket } \\
>3.5 \mathrm{~mm}\end{array}$ & 3 & $2.4(0.5-12.7)$ & $1.5(1.1-2.0)^{*}$ & $4.0(0.9-16.9)$ & $1.8(1.2-2.7)^{*}$ & $2.0(0.4-10.6)$ & $1.3(0.3-5.7)$ & $2.7(0.4-17.9)$ & $2.1(0.9-4.4)$ \\
\hline Healthy & 2 & 1 & 1 & 1 & 1 & 1 & 1 & 1 & 1 \\
\hline
\end{tabular}

countries. ${ }^{11,12,13}$ Moreover, our findings reveal the presence of decayed and/or missing teeth in more than $80 \%$ of the participants, results similar to those observed by Daly et al. ${ }^{12}$ and Lawder et al. ${ }^{17}$ Tooth loss can be the result of oral health neglect combined with the difficulty of access to dental care; caries is not diagnosed soon enough to carry out restorative treatment and teeth end up being extracted. ${ }^{32}$

Considered a worldwide public health problem, dental caries is associated with socioeconomic factors and difficulty or inability to access public services, ${ }^{33}$ which acutely affects less favored populations. ${ }^{32}$ The presence of decayed teeth in homeless persons resulted in a higher rate of negative impact on the total OHIP-14 score and on the domains of "physical pain", "psychological discomfort", "physical disability", and "social disability", compared with those who did not have caries. These findings can be explained by the absence of adequate biofilm control practices, leading to the impairing consequences of pain due to caries. ${ }^{12}$ Thus, our findings suggest that poor oral health conditions and pain negatively impact the OHRQoL of homeless persons, corroborating other studies with similar population and instruments. ${ }^{10,13,34}$
Decayed and missing teeth can also be risk factors for depressive conditions; in addition to decayed teeth being associated with negative impact in the "psychological discomfort" domain, the need for tooth extraction was the only clinical condition of OHIP-14 psychological disability. ${ }^{34}$ Tooth loss impairs not only the masticatory function, but also impacts an individual's psychological and social aspects. The need for tooth extraction implies that the tooth crown is extensively compromised by caries, which can have a detrimental esthetic effect. This can be the cause of social embarrassment, thus there is a negative impact on OHRQoL in the psychological disability domain. ${ }^{35}$

Socioeconomic condition is a risk factor for dental caries, which is why there is a polarization of the disease into less privileged social groups. ${ }^{36}$ Low income can be associated with placing less value on health, lifestyle, and access to health care information. ${ }^{35}$ Thus, the lack of access to preventive measures, and the under treatment of caries can have clinical consequences, as was observed in $42 \%$ of our study participants. The presence of a fistula, the most frequently found clinical consequence of untreated 
Factors associated with oral health-related quality of life in homeless persons: a cross-sectional study

Table 3. Multiple analysis between domains and total score of the OHIP- 14 with sociodemographic and oral health variables ( $\mathrm{n}=176$ ).

\begin{tabular}{|c|c|c|c|c|c|c|c|c|}
\hline \multirow{2}{*}{ Variable } & $\begin{array}{l}\text { Functional } \\
\text { limitation }\end{array}$ & $\begin{array}{l}\text { Physical } \\
\text { pain }\end{array}$ & $\begin{array}{l}\text { Psychological } \\
\text { discomfort }\end{array}$ & $\begin{array}{l}\text { Physical } \\
\text { disability }\end{array}$ & $\begin{array}{l}\text { Psychological } \\
\text { disability }\end{array}$ & $\begin{array}{c}\text { Social } \\
\text { disability }\end{array}$ & $\begin{array}{c}\text { Social } \\
\text { disadvantage }\end{array}$ & Total score \\
\hline & $\begin{array}{l}\mathrm{PR}_{\text {odiust }} \\
(95 \% \mathrm{Cl})\end{array}$ & $\begin{array}{l}\mathrm{PR}_{\text {odiust }} \\
(95 \% \mathrm{Cl})\end{array}$ & $\begin{array}{l}\mathrm{PR}_{\text {odiust }} \\
(95 \% \mathrm{Cl})\end{array}$ & $\mathrm{PR}_{\text {adjust }}(95 \% \mathrm{Cl})$ & $\mathrm{PR}_{\text {adiust }}(95 \% \mathrm{Cl})$ & $\begin{array}{l}\mathrm{PR}_{\text {odiust }} \\
(95 \% \mathrm{Cl})\end{array}$ & $\begin{array}{l}\mathrm{PR}_{\text {odiust }} \\
(95 \% \mathrm{Cl})\end{array}$ & $\begin{array}{l}\mathrm{PR}_{\text {odiust }} \\
(95 \% \mathrm{Cl})\end{array}$ \\
\hline \multicolumn{9}{|l|}{ Sex } \\
\hline Female & & $1.4(1.1-1.6)^{*}$ & & & $1.3(1.1-1.6)^{*}$ & & & \\
\hline Male & & 1 & & & 1 & & & \\
\hline \multicolumn{9}{|l|}{ Age (years) } \\
\hline Over 44 & & & & $1.8(1.2-2.7)^{*}$ & & & $1.7(1.1-2.8)^{*}$ & \\
\hline $37-43$ & & & & $1.6(1.0-2.5)$ & & & $1.6(0.9-2.6)$ & \\
\hline $30-36$ & & & & $1.6(1.0-2.4)$ & & & $1.6(0.9-2.6)$ & \\
\hline Up to 29 & & & & 1 & & & 1 & \\
\hline \multicolumn{9}{|l|}{ Marital status } \\
\hline $\begin{array}{l}\text { Married/Stable } \\
\text { relationship }\end{array}$ & $2.6(1.2-5.3)^{*}$ & & & & & & & \\
\hline $\begin{array}{l}\text { Single/Separated/ } \\
\text { Widowed }\end{array}$ & 1 & & & & & & & \\
\hline \multicolumn{9}{|c|}{ Schooling (in years of formal study) } \\
\hline$\leq 8$ & & & & $1.6(1.1-2.2)^{*}$ & & $2.0(1.3-3.0)^{*}$ & $1.9(1.4-2.8)^{*}$ & $1.4(1.1-1.8)^{*}$ \\
\hline$>8$ & & & & 1 & & 1 & 1 & 1 \\
\hline \multicolumn{9}{|l|}{ Decayed teeth } \\
\hline Yes & & $1.6(1.1-2.3)^{*}$ & $1.4(1.1-1.9)^{*}$ & $1.6(1.1-2.6)^{*}$ & & $\begin{array}{l}1.6(1.1- \\
2.5)^{*}\end{array}$ & & $1.4(1.1-1.8)^{\circ}$ \\
\hline No & & 1 & 1 & 1 & & 1 & & 1 \\
\hline \multicolumn{9}{|l|}{ Fistulas $>0$} \\
\hline Yes & $1.9(1.3-3.1)^{*}$ & & & & & & & \\
\hline No & 1 & & & & & & & \\
\hline \multicolumn{9}{|l|}{ Needs dental treatments } \\
\hline Restorative treatment & & & & & $1.0(0.3-2.9)$ & & & \\
\hline Prosthesis & & & & & $1.9(0.9-4.1)$ & & & \\
\hline Exodontia & & & & & $2.3(1.1-5.0)^{*}$ & & & \\
\hline No need & & & & & 1 & & & \\
\hline \multicolumn{9}{|l|}{$\mathrm{CPI}$} \\
\hline Bleeding & & $1.6(1.2-2.2)^{*}$ & & & & & & $1.7(1.1-2.7)^{*}$ \\
\hline Dental calculus & & $1.7(1.7-1.9)^{*}$ & & & & & & $1.8(1.3-2.5)^{*}$ \\
\hline Pocket $>3.5 \mathrm{~mm}$ & & $1.5(1.1-2.0)^{*}$ & & & & & & $1.8(0.9-3.2)$ \\
\hline Healthy & & 1 & & & & & & 1 \\
\hline
\end{tabular}

Model adjusted for: ulceration, PUFA, government benefit, marital status; $\mathrm{PR}_{\text {adjust }}$ : adjusted prevalence ratio; $95 \% \mathrm{Cl}$ : $95 \%$ confidence interval; ${ }^{*} p<0.05$.

dental caries in this study, negatively affected the "functional limitation" domain especially with regard to chewing, speech, and taste.

The "physical pain" domain was negatively influenced by the presence of gingival bleeding, dental calculus, and periodontal pocket deeper than $3.5 \mathrm{~mm}$, compared with individuals with healthy periodontal conditions. Gingival bleeding and dental calculus were also associated with a greater negative impact measured by the total OHIP-14 
score. Greater experience of pain and discomfort are expected findings in this population, ${ }^{34}$ which is probably due to less than adequate oral hygiene practices, poor oral health, and limited access to dental care. ${ }^{12,37}$

Homelessness represents greater challenges for women. This was corroborated by the higher prevalence rate of negative impact related to oral health in the domain of "physical pain" among homeless women. Pain and discomfort when eating more frequently reported by women can be explained by their greater biological sensitivity to stimuli and greater attention to health. ${ }^{38}$ Women have been traditionally perceived as more fragile and sensitive, express more the sensations and feelings, and being more proactive in the search for health care. ${ }^{7,39}$

Worse oral conditions associated with aging reveals the cumulative effects of a history of poor care and mutilating assistance. ${ }^{37,40}$ This may explain why individuals over the age of 44 years had a negative impact in the domains of "physical disability" and "social disadvantage" associated with the loss of multiple teeth. To make matters worse, the homeless population is a constant target of discrimination, which marginalizes them and creates stigmas of inferiority compared with other members of society. ${ }^{41}$ Thus, the difficulty of establishing bonds, obtaining physical and emotional support, and the frequent experience of violence can explain a greater negative impact in the "functional limitation" domain among those who are single, separated, or widowed.

Participants with low educational level had a greater negative impact on OHRQoL. Education has a direct impact on quality of life, ${ }^{42}$ which explains the findings of this study. Low education negatively affects the interaction of people in the community and access to health services, and consequently makes it difficult to carry out daily activities, in addition to the effects from social marginalization, prejudice, and discrimination.

For public policies in place in the country to be effective, they must ensure access to dental services for the population. ${ }^{2}$ It is important that health professionals and public policymakers are aware of these findings and can act in the improvement of oral health care and access for homeless persons.

Brazilian public health policies for the homeless population aim to guarantee the access of this population to health actions and services, reduce health risks arising from living conditions, and improve indicators of health and quality of life. ${ }^{2}$ To achieve this goal, Street Clinics Teams were created, which together with the Basic Health Units and Emergency Care Units, create access for the homeless population to the public health system. It is estimated that there are more than 100 Street Clinics Teams operating in Brazi, including in Teresina. ${ }^{20}$ However, dentists are not part of these teams and any person with dental treatment need is referred to Basic Health Units. The regrettable scenario revealed in our study could dramatically change for the better if dentists became members of such teams of professionals.

Our study makes an important contribution to one of the objectives of the National Policy for Homeless People, which is to encourage research and production and dissemination of knowledge about homelessness. ${ }^{2}$ The findings of our study can be used by authorities responsible for providing health actions and services to homeless people, help the implementation of measures to guarantee their right to health care, and reduce the burden that living conditions may impose on their health and quality of life.

Our study had some limitations. First, crosssectional data do not show the real cause of the impact on OHRQoL identified for this population. Moreover, although the choice for the most appropriate variables was supported by other studies in the literature, ${ }^{12,13,17}$ we might have accidentally overlooked variables that could have been included. A non-probabilistic sampling strategy was adopted due to the small number of individuals available for the study, and we acknowledge that extrapolation of the results is not possible to individuals outside the sample. In our favor, the participants in this study were contacted from a non-clinical setting, as in other studies. Therefore, we believe that the allocation bias was reduced, minimizing the possibility of favoring selection of participants with high oral health needs. Regarding the adopted 
instrument, although it has not been validated for homeless individuals, a recent systematic review of methods for evaluating outcomes in disadvantaged populations found that OHIP-14 is considered an applicable instrument for this population. ${ }^{9}$

Our study adds to the evidence on the well-being and living conditions of homeless persons and we recognize the need for further studies to confirm the directions of the effects signaled by our findings. The main contribution of our findings is showing that the oral health needs of homeless individuals are mostly not complex. Furthermore, although homeless people have physical and mental limitations, they are willing to receive most dental treatments. ${ }^{15}$

\section{Conclusion}

The negative impact on the OHRQoL of homeless persons was associated with low schooling, the presence of decayed teeth, gingival bleeding, and dental calculus.

\section{Acknowledgments}

This study is part of the master's dissertation of Raissa Marielly Parente Bernardino under the supervision of Dr. Regina Ferraz Mendes and was financed in part by the Coordenação de Aperfeiçoamento de Pessoal de Nível Superior Brasil (Capes) - Finance Code 001.

\section{References}

1. Clifford B, Wilson A, Harris P. Homelessness, health and the policy process: A literature review. Health Policy. 2019 Nov;123(11):1125-32. https://doi.org/10.1016/i.healthpol.2019.08.011

2. Brazil. Decreto No 7.053, de 23 de dezembro de 2009. Institui a Política Nacional para a População em Situação de Rua e seu Comitê Intersetorial de Acompanhamento e Monitoramento. Diário Oficial da União, Brasília, DF, 24 dez 2009.

3. United Nations. Report of the Special Rapporteur on adequate housing as a component of the right to an adequate standard of living, and on the right to non-discrimination in this context. General Assembly of Human Rights Council. Geneva: United Nations; 2015.

4. Nishio A, Horita R, Sado T, Mizutani S, Watanabe T, Uehara R, et al. Causes of homelessness prevalence: relationship between homelessness and disability. Psychiatry Clin Neurosci. 2017 Mar;71(3):180-8. https://doi.org/10.1111/pcn.12469

5. Mabhala MA, Yohannes A, Griffith M. Social conditions of becoming homelessness: qualitative analysis of life stories of homeless peoples. Int J Equity Health. 2017 Aug;16(1):150. https://doi.org/10.1186/s12939-017-0646-3

6. Yale University. Global homelessness statistics. 2017 [cited 2020 July 20]. Available in: https://homelessworldcup.org/homelessnessstatistics/

7. Aldridge RW, Story A, Hwang SW, Nordentoft M, Luchenski SA, Hartwell G, et al. Morbidity and mortality in homeless individuals, prisoners, sex workers, and individuals with substance use disorders in high-income countries: a systematic review and meta-analysis. Lancet. 2018 Jan;391(10117):241-50. https://doi.org/10.1016/S0140-6736(17)31869-X

8. Natalino MA. Estimativa da população em situação de rua no Brasil: setembro de 2012 a março de 2020). Brasília, DF: Instituto de Pesquisa Econômica Aplicada; 2016. (Nota técnica, n. 73).

9. Gordon SJ, Grimmer K, Bradley A, Direen T, Baker N, Marin T, et al. Health assessments and screening tools for adults experiencing homelessness: a systematic review. BMC Public Health. 2019 Jul;19(1):994. https://doi.org/10.1186/s12889-019-7234-y

10. Luo Y, McGrath C. Oral health and its impact on the life quality of homeless people in Hong Kong. Community Dent Health. 2008 Sep;25(3):137-42.

11. Pereira M, Oliveira L, Lunet N. Caries and oral health related behaviours among homeless adults from Porto, Portugal. Oral Health Prev Dent. 2014;12(2):109-16. https://doi.org/10.3290/i.ohpd.a31215

12. Daly B, Newton T, Batchelor P, Jones K. Oral health care needs and oral health-related quality of life (OHIP-14) in homeless people. Community Dent Oral Epidemiol. 2010 Apr;38(2):136-44. https://doi.org/10.1111/j.1600-0528.2009.00516.x

13. Ford PJ, Cramb S, Farah CS. Oral health impacts and quality of life in an urban homeless population. Aust Dent J. 2014 Jun;59(2):234-9. https://doi.org/10.1111/adj.12167

14. Conte M, Broder HL, Jenkins G, Reed R, Janal MN. Oral health, related behaviors and oral health impacts among homeless adults. J Public Health Dent. 2006;66(4):276-8. https://doi.org/10.1111/j.1752-7325.2006.tb04082.x

15. Coles E, Chan K, Collins J, Humphris GM, Richards D, Williams B, et al. Decayed and missing teeth and oral-health-related factors: predicting depression in homeless people. J Psychosom Res. 2011 Aug;71(2):108-12. https://doi.org/10.1016/i.jpsychores.2011.01.004 
16. Collins J, Freeman R. Homeless in North and West Belfast: an oral health needs assessment. Br Dent J. 2007 May;202(12):E31. https://doi.org/10.1038/bdj.2007.473

17. Lawder JA, Matos MA, Souza JB, Freire MD. Impact of oral condition on the quality of life of homeless people. Rev Saude Publica. 2019 Feb;53:22. https://doi.org/10.11606/S1518-8787.2019053000718

18. Sischo L, Broder HL. Oral health-related quality of life: what, why, how, and future implications. J Dent Res. 2011 Nov;90(11):1264-70. https://doi.org/10.1177/0022034511399918

19. Spector AL, Quinn KG, McAuliffe TL, DiFranceisco W, Bendixen A, Dickson-Gomez J. Health-related quality of life and related factors among chronically homeless adults living in different permanent supportive housing models: a cross-sectional study. Qual Life Res. 2020 Aug;29(8):2051-61. https://doi.org/10.1007/s11136-020-02482-w

20. Ministério da Saúde (BR). Saúde da população em situação de rua: um direito humano. Brasília, DF: Ministério da Saúde; 2014.

21. Silva ES, Possobon RF, Barbosa MD, Batista MJ, Tenuta LM. Impact of sense of coherence on oral health-related quality of life among Brazilian adults. Braz Oral Res. 2019 Oct;33:e100. https://doi.org/10.1590/1807-3107bor-2019.vol33.0100

22. Almoznino G, Gal N, Levin L, Mijiritsky E, Weinberg G, Lev R, et al. Diet practices, body mass index, and oral health-related quality of life in adults with periodontitis- a case-control study. Int J Environ Res Public Health. 2020 Mar; 17(7):2340. https://doi.org/10.3390/ijerph17072340

23. Machado Luz FW, Silva AER, Perroni AP, Goettems ML, Boscato N. Impact of Seniors Centers on oral health-related quality of life of older adults. Rev Saude Publica. 2020 Jan 20;54:7. https://doi.org/10.11606/s1518-8787.2020054001648

24. Patil S, Kahtani AA, Baeshen HA, Alamir AW, Khan S, Bhandi S, et al. Face validity and psychometric evaluation of the available oral health-related quality of life instruments: a systematic review. Oral Health Prev Dent. 2020;18(1):409-16. https://doi.org/10.3290/i.ohpd.a44680

25. Elm E, Altman DG, Egger M, Pocock SJ, Gøtzsche PC, Vandenbroucke JP. The Strengthening the Reporting of Observational Studies in Epidemiology (STROBE) statement: guidelines for reporting observational studies. J Clin Epidemiol. 2008 Apr;61(4):344-9. https://doi.org/10.1016/i.jclinepi.2007.11.008

26. World Health Organization. Oral health surveys: basic methods. 5th ed. Geneva: World Health Organization; 2013.

27. Ainamo J, Barmes D, Beagrie G, Cutress T, Martin J, Sardo-Infirri J. Development of the World Health Organization (WHO) community periodontal index of treatment needs (CPITN). Int Dent J. 1982 Sep;32(3):281-91.

28. Monse B, Heinrich-Weltzien R, Benzian H, Holmgren C, Palenstein Helderman W. PUFA: an index of clinical consequences of untreated dental caries. Community Dent Oral Epidemiol. 2010 Feb;38(1):77-82. https://doi.org/10.1111/j.1600-0528.2009.00514.x

29. Oliveira BH, Nadanovsky P. Psychometric properties of the Brazilian version of the Oral Health Impact Profile-short form. Community Dent Oral Epidemiol. 2005 Aug;33(4):307-14. https://doi.org/10.1111/j.1600-0528.2005.00225.x

30. Streiner DL, Norman GR. Health measurement scales: a pratical guide to their development and use. Oxford: Oxford University Press; 2008.

31. Hill KB, Rimington D. Investigation of the oral health needs for homeless people in specialist units in London, Cardiff, Glasgow and Birmingham. Prim Health Care Res Dev. 2011 Apr;12(2):135-44. https://doi.org/10.1017/S1463423610000368

32. Beaton L, Humphris G, Rodriguez A, Freeman R. Community-based oral health interventions for people experiencing homelessness: a scoping review. Community Dent Health. 2020 May;37(2):150-60. https://doi.org/10.1922/CDH_00014Beaton1 1

33. Chalub LL, Borges CM, Ferreira RC, Haddad JP, Ferreira EF, Vargas AM. Association between social determinants of health and functional dentition in 35-year-old to 44 -year-old Brazilian adults: a population-based analytical study. Community Dent Oral Epidemiol. 2014 Dec;42(6):503-16. https://doi.org/10.1111/cdoe.12112

34. Øzhayat EB, Østergaard P, Gotfredsen K. Oral health-related quality of life in socially endangered persons in Copenhagen, Denmark. Acta Odontol Scand. 2016 Nov;74(8):620-5. https://doi.org/10.1080/00016357.2016.1229022

35. Steele JG, Sanders AE, Slade GD, Allen PF, Lahti S, Nuttall N, et al. How do age and tooth loss affect oral health impacts and quality of life? A study comparing two national samples. Community Dent Oral Epidemiol. 2004 Apr;32(2):107-14. https://doi.org/10.1111/j.0301-5661.2004.00131.x

36. Peres MA, Macpherson LM, Weyant RJ, Daly B, Venturelli R, Mathur MR, et al. Oral diseases: a global public health challenge. Lancet. 2019 Jul;394(10194):249-60. https://doi.org/10.1016/S0140-6736(19)31146-8

37. Freitas DJ, Kaplan LM, Tieu L, Ponath C, Guzman D, Kushel M. Oral health and access to dental care among older homeless adults: results from the HOPE HOME study. J Public Health Dent. 2019 Dec;79(1):3-9. https://doi.org/10.1111/iphd.12288

38. Liddell A, Locker D. Gender and age differences in attitudes to dental pain and dental control. Community Dent Oral Epidemiol. 1997 Aug;25(4):314-8. https://doi.org/10.1111/j.1600-0528.1997.tb00945.x

39. Gomes R, Nascimento EF, Araújo FC. [Why do men use health services less than women? Explanations by men with low versus higher education]. Cad Saude Publica. 2007 Mar;23(3):565-74. Portuguese.

https://doi.org/10.1590/s0102-311×2007000300015

40. Raphael C. Oral health and aging. Am J Public Health. 2017 May;107 S1:S44-5. https://doi.org/10.2105/AJPH.2017.303835 
Factors associated with oral health-related quality of life in homeless persons: a cross-sectional study

41. Johnstone M, Jetten J, Dingle GA, Parsell C, Walter ZC. Discrimination and well-being amongst the homeless: the role of multiple group membership. Front Psychol. 2015 Jun;6:739. https://doi.org/10.3389/fpsyg.2015.00739

42. Papaioannou W, Oulis CJ, Latsou D, Yfantopoulos J. Oral health-related quality of life of greek adults: a cross-sectional study. Int J Dent. 2011;2011:360292. https://doi.org/10.1155/2011/360292 